\title{
Effectiveness of norfloxacin and ofloxacin for treatment of gonorrhoea and decrease of in vitro susceptibility to quinolones over time in Rwanda
}

Jos Bogaerts, Waldina Martinez Tello, Jeannete Akingeneye, Véronique Mukantabana, Eddy Van Dyck, Peter Piot

\begin{abstract}
Objective-To study the effectiveness of single-dose norfloxacin and ofloxacin in the treatment of gonococcal urethritis in men, and to monitor in vitro antimicrobial susceptibility to these antibiotics over time.
\end{abstract}

Setting-Centre Médico-Social de Bilyogo, Kigali, Rwanda. The only clinic in Rwanda using quinolones for the treatment of gonorrhoea.

Method-As part of a monitoring programme, men with gonococcal urethritis were evaluated after treatment with norfloxacin (800 mg) in 1986 and 1987, and after treatment with ofloxacin $(400 \mathrm{mg})$ in 1989.

Results-Neisseria gonorrhoeae was eradicated from the urethra from $96.0 \%$ (189/197) and from 97.1\% (166/171) men treated with norfloxacin and ofloxacin, respectively. Overall $38.2 \%$ of the pretreatment isolates produced penicillinase (PPNG isolates) and 20.4\% (44/216) of the tested non-PPNG isolates were chromosomally resistant to penicillin (MIC $\geq 2 \cdot 0$ mg/l). Resistance to tetracycline and thiamphenicol was common in both PPNG and non-PPNG and increased considerably in 1989. All isolates were susceptible to kanamycin, spectinomycin, ceftiaxone, norfloxacin, ofloxacin and ciprofloxacin. However, a higher number of isolates recovered in 1989 showed decreased susceptibility to the quinolones. Treatment failure occurred more often in subjects with isolates having MIC values $\geq 0.06 \mathrm{mg} / \mathrm{L}$ of norfloxacin $(p=0.006)$. Seven out of 13 patients who did not respond to therapy had no signs nor symptoms of urethritis.

Conclusion-Quinolone antibiotics are now indicated as a first line treatment of gonorrhoea in countries with a problem of antimicrobial multiresistance. However, antimicrobial susceptibility to the quinolones may decrease rapidly, and close monitoring of the in vitro susceptibility of $\boldsymbol{N}$ gonorrhoeae and the clinical effectiveness of the antibiotics is imperative.

(Genitourin Med 1993;69:196-200)

\section{Introduction}

Uncomplicated gonorrhoea is very frequent among young adults in Kigali, capital of
Rwanda, Central Africa. At the Centre Médico-Social de Bilyogo (CMS), Nyamirambo, Kigali, about 1500 new cases of gonococcal urethritis and cervicitis are diagnosed yearly. The CMS is a primary health care centre situated $3 \mathrm{~km}$ from the laboratory of the Centre Hospitalier de Kigali $(\mathrm{CHK})$, the only laboratory performing bacteriological cultures in the city and the prefecture of Kigali (population of 1,4000,000).

In 1985, a single oral dose of $800 \mathrm{mg}$ of norfloxacin cured $97.5 \%$ of patients in Kigali, and was significantly more effective than a single oral dose of $2.5 \mathrm{~g}$ of thiamphenicol. ${ }^{1}$ Because of the widespread existence of Neisseria gonorrhoeae resistant to penicillin, tetracycline and thiamphenicol, norfloxacin was selected as first line treatment of uncomplicated gonorrhoea in men and non-pregnant women, presenting at the CMS of Bilyogo. Norfloxacin is less expensive than both spectinomycin and cefotaxime, the only third generation cephalosporin available in Rwanda, and can be given by mouth. In 1989 , it was replaced by ofloxacin because of a shortage in the supply of norfloxacin.

We present here results of monitoring the efficacy of quinolones for the treatment of uncomplicated gonorrhoea, as well as the antimicrobial susceptibility patterns of gonococcal isolates over time in Kigali.

\section{Materials and methods}

Patient selection and study design

Patients included only adult men who presented with urethral discharge and who had not taken antibiotics within the preceding 72 hours. Patients were instructed to abstain from sexual contact until a negative follow up culture. Only patients from whom $N$ gonorrhoeae was isolated during the first visit and who returned for a follow up culture, 3 to 7 days after treatment, were included for evaluation. Classification of cure or failure was based on the results of the culture at the follow up visit.

In March, September and October 1986, and in May 1987, respectively, 254 and 103 consecutive men received a $800 \mathrm{mg}$ single oral dose of norfloxacin. A total of $318 \mathrm{men}$ who visited the centre in May, June, October, November and December 1989 were given a $400 \mathrm{mg}$ single oral dose of ofloxacin. At the follow up visit all patients, except those seen in 1987, were interviewed about complaints of dysuria, and the presence of a discharge was recorded. Postgonococcal urethritis was 
defined as the presence of a urethral discharge with a negative gonococcal culture after treatment.

\section{Gonococcal culture and antimicrobial susceptibility testing}

Urethral specimens were immediately inoculated onto Thayer-Martin medium and incubated in a candle jar at $37^{\circ} \mathrm{C}$ for 3 days. Gram staining on the discharge was not performed. Isolates were identified as $N$ gonorrhoeae by standard techniques and were tested for $\beta$-lactamase by the chromogenic cephalosporin (Nitrocefin; Oxoid Ltd.) technique. All isolates were kept in skim milk at $-80^{\circ} \mathrm{C}$ and shipped to Belgium for confirmatory identification and susceptibility testing.

Minimal inhibitory concentrations (MICs) were determined by an agar dilution method on GC agar (Oxoid) supplemented with $1 \%$ IsoVitaleX (BBL Microbiology Systems, Cockeysville, Md.). The inoculum, corresponding to $10^{4}$ colony forming units per spot, was delivered with a multipoint inoculator. MIC plates were incubated for $24 \mathrm{~h}$ at $37^{\circ} \mathrm{C}$ in a $5 \% \quad \mathrm{CO}_{2}$ atmosphere. The MIC was read as the lowest concentration of the antimicrobial agent that allowed no visible growth.

\section{Results}

Treatment results

Three hundred and one $(84 \cdot 3 \%)$ out of 357 consecutive men who received norfloxacin had culture proven gonorrhoea at the first visit. Of the patients with gonorrhoea, 197 $(65.4 \%)$ returned for a follow up visit (129 in 1986,68 in 1987). Among the 301 pretreatment isolates, $109(36.2 \%)$ produced $\beta$-lactamase. The proportion of penicillinase producing $N$ gonorrhoeae isolates (PPNG) was lower among evaluable patients than among subjects who did not return for follow up $(64 / 197$ or $32.5 \%$ versus $45 / 104$ or $43.3 \% ; \mathrm{p}=0 \cdot 07)$.

Two hundred and forty nine $(78 \cdot 3 \%)$ out of 318 men who received ofloxacin had culture proven gonorrhoea. One hundred and seventy two $(69 \cdot 1 \%)$ of the gonorrhoea patients returned for follow up. One of them admitted re-exposure and was excluded for evaluation. Among the 249 pretreatment isolates, $101(40.6 \%)$ were PPNG. PPNG isolates were equally frequent in evaluable and non evaluable patients $(69 / 171$ or $40.4 \%$ versus $32 / 78$ or $41.0 \%$ ).

After a single dose of norfloxacin, 121

Table 1 Results of treatment with norfloxacin and ofloxacin in men with uncomplicated gonorrhoea

\begin{tabular}{llllc}
\hline $\begin{array}{l}\text { Treatment } \\
\text { regimen } \\
\text { (years) }\end{array}$ & $\begin{array}{l}\text { No. of } \\
\text { evaluable } \\
\text { patients }\end{array}$ & $\begin{array}{l}\text { \% with } \\
P P N G^{*}\end{array}$ & $\begin{array}{l}\text { No. of } \\
\text { patients } \\
\text { cured (\%) }\end{array}$ & $\begin{array}{l}\text { Post treatment urethral } \\
\text { discharge } \\
\text { in cured patients (\%) }\end{array}$ \\
\hline $\begin{array}{l}\text { Norfloxacin } \\
(1986-1987)\end{array}$ & 197 & 32.5 & $189(96 \cdot 0)$ & $6 \cdot 7$ \\
$\begin{array}{c}\text { Ofloxacin } \\
(1989)\end{array}$ & 171 & 40.4 & $166(97 \cdot 1)$ & $12 \cdot 7$ \\
\hline
\end{tabular}

^Penicillinase producing Neisseria gonorrhoeae.
(93.8\%) out of 129 men were bacteriologically cured in 1986 and there were no failures among the 68 patients treated in 1987. The overall cure rate was estimated at $96.0 \%$ (189/197) (table 1). Clinical symptoms of urethritis persisted in only three men who failed to respond to therapy, including two patients with dysuria and discharge, and one with dysuria only. The five remaining men who were still culture positive after therapy, had no urethral discharge nor symptoms of urethritis at 3 days following treatment. Eight $(6 \cdot 7 \%)$ out of 121 bacteriologically cured patients had a posttreatment discharge and another $16(13.2 \%)$ had complaints of dysuria without a discharge. Overall, five $(4.9 \%)$ out of 102 clinically cured patients (only patients from 1986 were interviewed) had still a positive control culture.

In the ofloxacin group, $166(97 \cdot 1 \%)$ out of the 171 evaluable patients were cured bacteriologically (table 1). Clinical symptoms of urethritis persisted in three out of five patients who had a positive test-of-cure culture, including two with dysuria and discharge and one with only a discharge. Twenty-one $(12.7 \%)$ cured patients had a discharge posttreatment. Complaints of dysuria without discharge persisted in $52(31.3 \%)$ others. Overall, two $(2 \cdot 1 \%)$ out of 95 men with clinically cured gonorrhoea had still a positive control culture.

\section{Antimicrobial susceptibility of $N$ gonorrhoeae and correlation with treatment outcome} MIC results were available for $200(66.4 \%)$ and $143(57 \cdot 4 \%)$ pretreatment isolates from the men treated with norfloxacin and ofloxacin, respectively. For posttreatment isolates, MIC values were available for respectively five and three patients who failed therapy. All isolates were fully susceptible to kanamycin and spectinomycin (MIC, $\leq 32$ $\mathrm{mg} / \mathrm{l}$ ), and to ceftriaxone (MIC, $\leq 0.06 \mathrm{mg} / \mathrm{l}$ ) (table 2).

The prevalence of PPNG in the original sample of pretreatment isolates was somewhat higher in 1989 than in $1986 / 1987$ ( $40.6 \%$ versus $36 \cdot 2 \%)$. However, the proportion of PPNG among all isolates recovered at the laboratory of the CHK has been fairly constant since 1984 (unpublished data).

In non-PPNG isolates, chromosomal type resistance to penicillin (MIC, $\geq 2.0 \mathrm{mg} / \mathrm{l}$ ) was significantly more common in 1989 than in $1985\left(38.8 \%\right.$ versus $14.6 \% ; \chi^{2}=7.57 ; \mathrm{p}=$ 0.006). Similarly, resistance to thiamphenicol (MIC, $\geq 2 \mathrm{mg} / \mathrm{l}$ ) was not diagnosed in 1985 but reached $71 \cdot 8 \%$ of non-PPNG and $43 \cdot 2 \%$ of PPNG isolates in 1989. In non-PPNG, resistance to tetracycline (MIC, $\geq 4 \mathrm{mg} / \mathrm{l}$ ) was observed in $60.0 \%$ of isolates during 1989 , as compared with $26.8 \%$ of isolates during 1985 $\left(\chi^{2}=12 \cdot 18 ; \mathrm{p}<0.001\right)$. High-level plasmidmediated resistance to tetracycline (MIC, $\geq 16 \mathrm{mg} / \mathrm{l}$ ) was not seen in our study population but emerged in Kigali during 1989 after the end of this study.

In 1985 , only a single non-PPNG isolate showed a MIC value of $0 \cdot 125 \mathrm{mg} / 1$ of nor- 
Table 2 Evolution of in vitro susceptibility of N. gonorrhoeae isolates from Kigali

\begin{tabular}{|c|c|c|c|c|c|c|c|}
\hline \multirow[b]{2}{*}{$\begin{array}{l}\text { Antimicrobial } \\
\text { agent }\end{array}$} & \multirow[b]{2}{*}{$\begin{array}{l}M I C \\
(m g / l)\end{array}$} & \multicolumn{2}{|l|}{$1985^{\star}$} & \multicolumn{2}{|c|}{$1986-1987$} & \multicolumn{2}{|l|}{1989} \\
\hline & & $\begin{array}{l}P P N G \\
N=22 \\
\%\end{array}$ & $\begin{array}{l}\text { non } P P N G \\
N=41 \\
\%\end{array}$ & $\begin{array}{l}P P N G \\
N=69 \\
\%\end{array}$ & $\begin{array}{l}\text { non } P P N G \\
N=131 \\
\%\end{array}$ & $\begin{array}{l}P P N G \\
N=58 \\
\%\end{array}$ & $\begin{array}{l}\text { non } P P N G \\
N=85 \\
\%\end{array}$ \\
\hline Penicillin G & $\begin{array}{l}<0.50 \\
0.50-1.0 \\
>2.0\end{array}$ & $\frac{\bar{T}}{100}$ & $\begin{array}{l}63 \cdot 4 \\
22 \cdot 0 \\
14 \cdot 6\end{array}$ & $\frac{-}{100}$ & $\begin{array}{r}42 \cdot 0 \\
49 \cdot 6 \\
8.4\end{array}$ & $\frac{-}{100}$ & $\begin{array}{l}27 \cdot 1 \\
34 \cdot 1 \\
38 \cdot 8\end{array}$ \\
\hline Tetracycline & $\begin{array}{r}22.0 \\
\leq 1.0 \\
2 \cdot 0 \\
\geq 4.0\end{array}$ & $\begin{array}{r}31 \cdot 8 \\
31 \cdot 8 \\
36.4\end{array}$ & $\begin{array}{l}14.0 \\
19 \cdot 5 \\
53 \cdot 7 \\
26.8\end{array}$ & $\begin{array}{r}68 \cdot 1 \\
17 \cdot 4 \\
14.5\end{array}$ & $\begin{array}{r}0.4 \\
56.5 \\
19 \cdot 8 \\
23.7\end{array}$ & $\begin{array}{r}55 \cdot 2 \\
15 \cdot 5 \\
29 \cdot 3\end{array}$ & $\begin{array}{l}27 \cdot 1 \\
12 \cdot 9 \\
60 \cdot 0\end{array}$ \\
\hline Thiamphenicol & $\begin{array}{r}\leq 0.5 \\
1.0 \\
\geq 2.0\end{array}$ & $\begin{array}{l}45 \cdot 5 \\
54 \cdot 5 \\
\end{array}$ & $\begin{array}{l}48 \cdot 8 \\
51 \cdot 2 \\
-\end{array}$ & $\begin{array}{l}44.9 \\
23.2 \\
31.9\end{array}$ & $\begin{array}{l}22 \cdot 1 \\
29 \cdot 0 \\
48.9\end{array}$ & $\begin{array}{l}37.9 \\
18.9 \\
43.2\end{array}$ & $\begin{array}{l}12.9 \\
15 \cdot 3 \\
71 \cdot 8\end{array}$ \\
\hline Norfloxacin & $\begin{array}{c}\leq 0.03 \\
0.06 \\
\geq 0.125\end{array}$ & $\begin{array}{l}50.0 \\
50.0 \\
-\quad\end{array}$ & $\begin{array}{r}61 \cdot 0 \\
36 \cdot 6 \\
2 \cdot 4\end{array}$ & $\begin{array}{r}69 \cdot 6 \\
24 \cdot 6 \\
5 \cdot 8\end{array}$ & $\begin{array}{r}55 \cdot 7 \\
39 \cdot 7 \\
4 \cdot 6\end{array}$ & $\begin{array}{l}67 \cdot 2 \\
12 \cdot 1 \\
20 \cdot 7\end{array}$ & $\begin{array}{l}38 \cdot 9 \\
22 \cdot 3 \\
38 \cdot 8\end{array}$ \\
\hline Ofloxacint & $\begin{array}{c}\leq 0.03 \\
0.06 \\
\geq 0.125\end{array}$ & & & $\begin{array}{r}95.6 \\
4.4 \\
-\quad\end{array}$ & $\begin{array}{r}97.2 \\
5.8 \\
-\end{array}$ & $\begin{array}{r}81 \cdot 0 \\
17 \cdot 2 \\
1.8\end{array}$ & $\begin{array}{r}67 \cdot 1 \\
31 \cdot 8 \\
1 \cdot 1\end{array}$ \\
\hline Ciprofloxacin $†$ & $\begin{array}{r}\leq 0.03 \\
0.06\end{array}$ & & & $\underline{100}$ & $\underline{100}$ & $\begin{array}{r}98 \cdot 3 \\
1.7\end{array}$ & $\begin{array}{r}98 \cdot 8 \\
1 \cdot 2\end{array}$ \\
\hline
\end{tabular}

${ }^{\star}$ Reference 1.
†Only 45 PPNG and 86 non PPNG from 1986/1987 were tested. Ofloxacin and ciprofloxacin were not tested in 1985.

floxacin, but MIC values of $\geq 0 \cdot 125 \mathrm{mg} / 1$ were observed in $20.7 \%$ of PPNG and in $38.8 \%$ of non-PPNG in 1989. Decreasing in vitro susceptibility was also observed for ofloxacin. In 1989 already $19.0 \%$ of PPNG and $32.9 \%$ of non-PPNG had MIC values of $\geq 0.06 \mathrm{mg}$ of ofloxacin $/ \mathrm{ml}$. In contrast in $1986 / 1987$, only $4.4 \%$ and $5.8 \%$ of PPNG and non-PPNG showed MIC values of $0.06 \mathrm{mg} / \mathrm{l}$ of ofloxacin.

Table 3 shows the MIC geometric mean values of all tested antibiotics for $N$ gonorrhoeae isolates with low and increased MICs of norfloxacin and ofloxacin. Decreased susceptibility to norfloxacin (MIC $\geq 0.125 \mathrm{mg} / \mathrm{l}$ ) and decreased susceptibility to ofloxacin (MIC $\geq 0.06 \mathrm{mg} / \mathrm{l}$ ) were significantly associated with higher MIC values of all other antimicrobials.

Patients infected with gonococcal strains exhibiting an MIC of $\geq 0.06 \mathrm{mg} / 1$ of norfloxacin more often failed therapy with this antibiotic than patients infected with more susceptible strains (fig). The failure rates on norfloxacin therapy were respectively $2 / 87$ $(2 \cdot 3 \%), 4 / 43(9 \cdot 3 \%)$ and $2 / 8(25 \cdot 0 \%)$ for MIC values of $\leq 0.03 \mathrm{mg} / 1,0.06 \mathrm{mg} / 1$ and $\geq 0.125 \mathrm{mg} / 1$ of norfloxacin $\left(\chi_{\text {trend }}^{2}: 7 \cdot 66 ; \mathrm{p}=\right.$ 0.006). For four patients who did not respond to norfloxacin, paired pre-treatment/post-treatment gonococcal isolates were available for susceptibility testing giving
MICs of $0.015 / 0.06,0.06 / 0.06,0.06 / 0 \cdot 125$, and $0 \cdot 125 / 0 \cdot 125 \mathrm{mg} / 1$ of norfloxacin respectively. Overall, six out of eight men who failed to respond to therapy, and $45(34.6 \%)$ out of 130 cured patients harboured isolates with MIC values $\geq 0.06 \mathrm{mg} / \mathrm{l}$ of norfloxacin (Fisher's exact test, 2-tailed: $p=0.051$ ).

Of four patients who did not respond to ofloxacin, two harboured an isolate with a MIC value $\leq 0.03 \mathrm{mg} / \mathrm{l}$, and two with a MIC of $0.06 \mathrm{mg} / \mathrm{l}$ of ofloxacin. Paired pre-treatment/post-treatment gonococcal isolates were tested for two of these patients; the corresponding MICs were $0 \cdot 06 / 0.015$ and $0 \cdot 008 / 0.008 \mathrm{mg} / 1$ of ofloxacin.

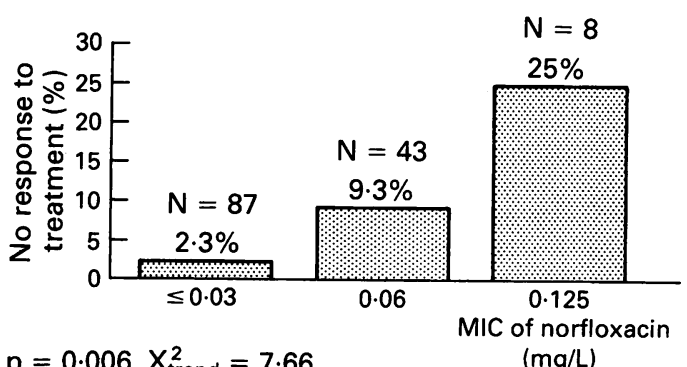

Figure Correlation between treatment outcome and in vitro susceptibility to norfloxacin

Table $3 \mathrm{~N}$ gonorrhoeae MIC values (geometric means) of different antimicrobial agents with respect to in vitro susceptibility of norfloxacin (343 isolates) and ofloxacin (274 isolates)

\begin{tabular}{|c|c|c|c|c|c|c|}
\hline \multirow[b]{3}{*}{ Antimicrobial } & \multicolumn{2}{|c|}{ MIC norfloxacin $(\mathrm{mg} / \mathrm{l})$} & \multirow[b]{3}{*}{$p^{*}$} & \multicolumn{2}{|c|}{ MIC ofloxacin (mg/l) } & \multirow[b]{3}{*}{$p^{*}$} \\
\hline & $\leq 0.06$ & $\geq 0 \cdot 125$ & & $\leq 0.03$ & $\geq 0.06$ & \\
\hline & $N=288$ & $N=55$ & & $N=228$ & $N=46$ & \\
\hline $\begin{array}{l}\text { Penicillin† } \\
\text { Tetracycline } \\
\text { Thiamphenicol } \\
\text { Kanamycin } \\
\text { Spectinomycin } \\
\text { Ceftriaxone } \\
\text { Ciprofloxacin } \\
\text { Ofloxacin } \\
\text { Norfloxacin }\end{array}$ & $\begin{array}{l}0.44 \\
1.32 \\
0.92 \\
16.78 \\
22.33 \\
0.005 \\
0.005 \\
0.014 \\
-\end{array}$ & $\begin{array}{l}2.03 \\
3.78 \\
2.50 \\
24 \cdot 5 \\
26 \cdot 6 \\
0.014 \\
0.020 \\
0.054 \\
-\end{array}$ & $\begin{array}{r}<0.001 \\
<0.001 \\
<0.001 \\
<0.001 \\
0.009 \\
<0.001 \\
<0.001 \\
<0.001\end{array}$ & $\begin{array}{c}0.58 \\
1.35 \\
0.98 \\
19.23 \\
21.72 \\
0.005 \\
0.005 \\
-0.03\end{array}$ & $\begin{array}{c}2 \cdot 17 \\
3 \cdot 89 \\
2 \cdot 61 \\
27 \cdot 28 \\
27 \cdot 73 \\
0.015 \\
0.018 \\
-0.125\end{array}$ & $\begin{aligned}<0.001 \\
<0.001 \\
<0.001 \\
<0.001 \\
0.001 \\
<0.001 \\
<0.001 \\
\quad<0.001\end{aligned}$ \\
\hline
\end{tabular}




\section{Discussion}

The present study once more documents the staggering problem of multiresistance among $N$ gonorrhoeae isolates in Africa. Both norfloxacin and ofloxacin as a single dose were highly effective for the treatment of uncomplicated gonorrhoea due to multiresistant strains in men, with cure rates of over $95 \%$. Treatment failure with norfloxacin was associated with decreased in vitro susceptibility to this quinolone.

During 1985-1988, norfloxacin was exclusively used for treatment of uncomplicated gonorrhoea at the CMS clinic of Bilyogo. The product was not available elsewhere in the country, though a total of 500 tablets (each containing $400 \mathrm{mg}$ of norfloxacin) were imported by the major drug importer in the middle of 1987 and were exclusively sold in one private pharmacy in Kigali. In $1986 / 1987$, patients with gonorrhoea who presented at the CMS harboured more frequently isolates with MIC values $\geq 0.06 \mathrm{mg} / 1$ of norfloxacin than patients who were treated elsewhere (unpublished data). In 1989, 5 years after the introduction of norfloxacin in a single clinic, a significantly higher proportion of isolates had MIC values $\geq 0.125 \mathrm{mg} / 1$ of norfloxacin. Similarly, ofloxacin was not imported in Rwanda before 1989 and its use was strictly limited to patients consulting the CMS clinic. The proportion of strains showing MIC values $\geq 0.06 \mathrm{mg} / 1$ of ofloxacin was also higher during 1989 than during 1986-1987.

These results confirm that strains, relatively resistant to one quinolone, have also decreased susceptibility to other members of the group, ${ }^{23}$ and that even limited use of quinolones in a community fairly rapidly leads to a gradual development of antimicrobial resistance. The studies also suggest that decreasing in vitro susceptibility of $N$ gonorrhoeae, at least to norfloxacin, is associated with a decreasing therapeutic efficacy of the quinolones. Therefore, it is of utmost public health importance that the in vitro susceptibility and/or therapeutic efficacy of quinolones be closely monitored when these are recommended and used for the treatment of gonorrhoea in a country.

In spite of the absence of signs or symptoms of urethritis, seven $(3.6 \%)$ out of 197 clinically cured patients from both treatment regimens had still a positive gonococcal culture at 3 to 7 days after therapy. The relative frequency of asymptomatic carriers of $N$ gonorrhoeae after apparently successful treatment with a single dose of a quinolone, and the risk of transmitting such isolates is unknown. Among the five asymptomatic men from the norfloxacin failure group, only three posttreatment isolates were available for sensitivity testing (MICs, $0.06 \mathrm{mg} / \mathrm{l}, 0.125 \mathrm{mg} / \mathrm{l}$ and $0.125 \mathrm{mg} / 1$ of norfloxacin). A single posttreatment isolate was tested from the two asymptomatic ofloxacin failures (MIC of $0.015 \mathrm{mg} / 1$ of ofloxacin). This suggests that isolates from asymptomatic patients who failed therapy had similar susceptibility patterns than those from symptomatic patients who did not respond. Although an incubating reinfection cannot be excluded in these asymptomatic patients, this seems unlikely as all men were seen within six days after treatment. Finally, it may be that a single dose of $800 \mathrm{mg}$ norfloxacin for an infection caused by a strain with MIC values $\geq 0.125 \mathrm{mg} / 1$ of norfloxacin results in a significant reduction of bacterial numbers, but without eradication. Clinical manifestations may then rapidly disappear when most of the pathogens are killed, but culture remains positive, and disease may relapse when bacterial numbers reach a critical threshold in the urethra. As patients were not requested to come back after 7 days, this hypothesis could not be verified. It is not clear whether asymptomatic carriership is more common after therapy with quinolones, than with other antibiotics, but our results stress the need for a bacteriological test of cure when monitoring the efficacy of recommended treatment regimens.

The World Health Organization recently proposed regimens for the treatment of uncomplicated gonorrhoea for areas with a high prevalence of PPNG or chromosomally resistant strains. These regimens include, as single doses, ceftriaxone $(250 \mathrm{mg}$ by intramuscular injection), ciprofloxacin (500 mg per os) and spectinomycin ( $2 \mathrm{~g}$ by intramuscular injection). In many developing countries third generation cephalosporins are not available, and are too expensive for the first line treatment of gonorrhoea. Spectinomycin is widely available but it is also expensive and must be given in intramuscular injection. ${ }^{4}$ Quinolone antibiotics are highly effective for the treatment of uncomplicated gonorrhoea and even of gonococcal keratoconjunctivitis in adults. ${ }^{15-13}$ They offer the advantage of oral administration, but cannot be given to children aged under 16 years or to pregnant women, and the risk for rapid development of resistance may be higher than with other antibiotics. ${ }^{14-18}$ In addition, the high prevalence of the human immunodeficiency virus (HIV) in Central Africa, especially in patients with sexually transmitted diseases, makes oral therapy preferable over parenteral administration of drugs to decrease the risk of parenteral transmission of HIV. Finally, from a public health point of view it seems desirable that a highly effective treatment regimen for gonorrhoea be used, even if such a drug is slightly more expensive than less effective alternatives such as the now widely used kanamycin. Such an approach should benefit both the patient (by reducing the risk of complications) and the community (by slowing down the development of antimicrobial resistance and by decreasing the duration of infectivity of patients which reduces the transmission of gonorrhoea).

Despite the problems mentioned above, quinolones are now indicated as a first line treatment of gonorrhoea in countries with a problem of antimicrobial multiresistance, provided that the antimicrobial susceptibility of $N$. gonorrhoeae and clinical effectiveness of the quinolones be closely monitored. 
We thank Prof. J. Vandepitte, Catholic University of Leuven, and Mr. Bruylandt and Mr. Lagneau, Hoechst Belgium, for providing ofloxacin. We also thank Mr. Davite, Kipharma, Kigali for his help.

1 Bogaerts J, Martinez Tello W, Verbist L, Piot P, Vandepitte J. Norfloxacin versus thiamphenicol for treatment of uncomplicated gonorrhea in Rwanda. Antimicrob Agents Chemother 1987;31:434-7.

2 Van Klingeren V, Dessens-Kroon $M$, Verheuvel $M$. In vitro activity of quinolones against penicillinase-producing and non-penicillinase-producing gonococci. Chemotherapia 1985;4 (Suppl.2):464-5.

3 Smith JT. The mode of action of 4-quinolones and possible mechanisms of resistance. F Antimicrob Chemother 1986;18 (Suppl.D):21-9.

4 Management of Patients with Sexually Transmitted Diseases. Report of a WHO Study Group. WHO Technical Report of a WHO Study Group.
Reports Series No. 810. Geneva 1991.

5 Aznar J, Prados R, Herrera A, Rodiguez-Pichardo A, Pera EJ. Single doses of ofloxacin in uncomplicated gonorrhoea. Drugs 1987;34 (Suppl.1):107-10.

6 Richmond SJ, Bhattacharyya MN, Mati H, Chowdhury FH, Stirland RM, Tooth JA. The efficacy of ofloxacin against infection caused by Neisseria gonorrhoeae and Chlamydia trachomatis. I Antimicrob Chemother 1988;22 (Suppl. C):149-53.

7 Rajakumar MK, Ngeow YF, Khor BS, Lim KF. Ofloxacin, a new quinolone for the treatment of gonorrhea. Sex Transm Dis 1988;15:25-6.

8 Black JR, Long JM, Zwickl BE, et al. Multicenter randomized study of single-dose ofloxacin versus amoxicillinprobenecid for treatment of uncomplicated gonococcal infection. Antimicrob Agents Chemother 1989;33:167-70.
9 Covino JM, Cummings M, Smith B, Benes S, Draft K, McCormack W. Comparison of ofloxacin and ceftriaxone in the treatment of uncomplicated gonorrhea caused by penicillinase-producing and non-penicillinase-producing strains. Antimicrob Agents Chemother nase-producing
$1990 ; 34: 148-9$

10 Moran JS, Zenilman JM. Therapy for gonococcal infections: options in 1989. Rev Infect Dis 1990;12: (Suppl 6): 633-644.

11 Smith BL, Cumming MC, Covino JM, Benes S, Draft K, McCormack WM. Evaluation of ofloxacin in the of uncomplicated gonorrhea Sex Transm Dis 1991;18:18-20.

12 Cheong LL, Chan RKW, Nadaraja M. Perfloxacin and ciprofloxacin in the treatment of uncomplicated gonococcal urethritis in males. Genitourin Med 1992;68:260-2.

13 Kestelyn P, Bogaerts J, Stevens AM, Piot P, Meheus A. Treatment of adult gonococcal keratoconjunctivitis with oral norfloxacin. Am $\mathcal{F}$ Ophthalmol 1989;108:516-23.

14 Jephcott $\mathrm{AE}$, Turner $\mathrm{A}$. Ciprofloxacin resistance in gonococci. Lancet 1990;335:759.

15 Turner A, Jephcott AE, Haji TC, Gupta PC. Ciprofloxacin resistant Neisseria gonorrhoeae in the UK. Genitourin Med 1990;66:43-6.

16 Ison CA, Branley NS, Kirtland $K$, Easmon CSF. Surveillance of antibiotic resistance in clinical isolates of Neisseria gonorrhoeae. BMF 1991;303:1307.

17 Gransden WF, Warren CA, Phillips I, Hodges M, Barlow D. Decreased susceptibility of Neisseria gonorrhoeae to D. Decreased susceptibility of $N$ ciprofloxacin. Lancet 1990;333:51.
cipro

18 Young H, Moyes A, Tait IB, McCartney AC, Gallacher G. Non-typable quinolone-resistant gonoccoci. Lancet 1990;335:604. 